\title{
The Detection of Liquid Organic Solvents on Metal Oxide Nanostructure Decorated Porous Silicon Interfaces
}

\author{
Caitlin Baker ${ }^{\mathrm{a}}$, and James L. Gole, ${ }^{\mathrm{a}, \mathrm{b}, *}$
}

${ }^{a}$ School of Physics, Georgia Institute of Technology, Atlanta, Georgia 30332, USA

${ }^{\mathrm{b}}$ School of Mechanical Engineering, Georgia Institute of Technology, Atlanta, Georgia 30332 USA

*Corresponding author: 837 State Street, Atlanta, GA, 30332-0430, USA, Tel: +1-404894-4029; Email: James.Gole@physics.gatech.edu

This Supporting Information document includes additional figures and tables illustrating the interaction of liquid organic solvents within the pores of $\mathrm{p}$ - and n-type porous silicon (PSi) interfaces.

Table of Contents

\begin{tabular}{|c|c|c|}
\hline Figure S1 & Schematic diagram of a Simplified Randles Cell & S-2 \\
\hline Table S1 & Parameter values for $n$-type equivalent circuit model & S-2 \\
\hline Table S2 & Parameter values for p-type equivalent circuit model & S-2 \\
\hline Table S3 & N-type equivalent circuit values in wet conditions & S-3 \\
\hline Table S4 & $\begin{array}{l}\text { Percentage changes in equivalent circuit elements for p-type PSi } \\
\text { sensors upon application of organic solvents }\end{array}$ & S-4 \\
\hline Figure S2 & N-type Nyquist plots for polar and non-polar organic solvents & S-4 \\
\hline Figure S3 & P-type Nyquist plots for polar organic solvents & S-5 \\
\hline Figure S4 & P-type Nyquist plots for non-polar organic solvents & S-6 \\
\hline Figure S5 & $\mathrm{N}$-type conductance and capacitance plots at $100 \mathrm{~Hz}$ and $100 \mathrm{kHz}$ & S-6 \\
\hline Figure S6 & N-type conductance and capacitance plots for polar and non-polar & S-7 \\
\hline Figure S7 & P-type conductance and capacitance plots for polar solvents & S-8 \\
\hline Figure S8 & P-type conductance and capacitance plots for non-polar solvents & S-9 \\
\hline Figure S9 & P-type conductance and capacitance plots at $100 \mathrm{~Hz}$ and $100 \mathrm{kHz}$ & S-9 \\
\hline Figure S10 & P-type Nyquist plots comparing metal oxide depositions & S-10 \\
\hline Figure S11 & $\begin{array}{l}\text { N-type Nyquist plots of isopropanol and acetone comparing blank } \\
\text { sensor and metal oxide deposited sensor }\end{array}$ & S-10 \\
\hline Figure S12 & $\begin{array}{l}\text { N-type Nyquist plots of toluene and chloroform comparing blank } \\
\text { sensor and metal oxide deposited sensor }\end{array}$ & S-11 \\
\hline
\end{tabular}




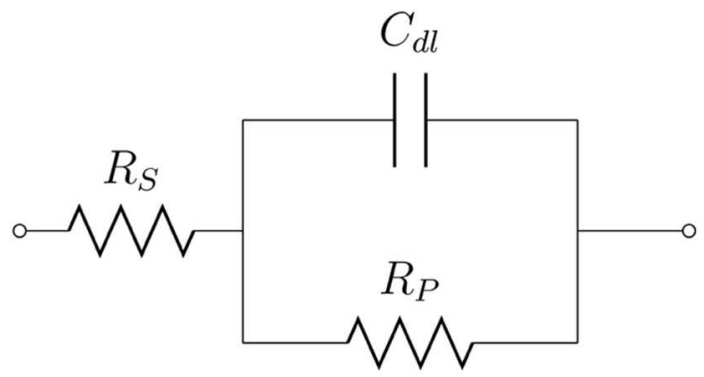

Figure S1. Schematic diagram of a Simplified Randles Cell.

Table S1. Parameter values for the equivalent circuit model describing an n-type PSi sensor in dry air at atmospheric temperature and pressure. The minimized sum of squares for this model is $\boldsymbol{Q}=\mathbf{1 . 1 6 3 6}$ and the standard deviation of error is $\boldsymbol{\sigma}=\mathbf{0 . 0 3 7}$.

\begin{tabular}{lll}
\hline Circuit element & Value & Unit \\
\hline $\mathrm{R}_{\mathrm{S}}$ & $1 \times 10^{-7}$ & $\Omega$ \\
$\mathrm{C}$ & $1.138 \times 10^{-8}$ & $\mathrm{~F}$ \\
$\mathrm{P}$ & 0.8302 & \\
$\mathrm{R}_{1}$ & 17554 & $\Omega$ \\
\hline
\end{tabular}

Table S2. Parameter values for the equivalent circuit model describing a p-type PSi sensor in dry air at atmospheric temperature and pressure. The minimized sum of squares for this model is $\boldsymbol{Q}=\mathbf{0 . 6 8 4 4}$ and the standard deviation of error is $\boldsymbol{\sigma}=\mathbf{0 . 0 2 2}$.

\begin{tabular}{lll} 
Circuit element & Value & Unit \\
\hline $\mathrm{R}_{\mathrm{S}}$ & 287.4 & $\Omega$ \\
$\mathrm{C}_{1}$ & $5.2961 \times 10^{-9}$ & $\mathrm{~F}$ \\
$\mathrm{R}_{1}$ & 1103 & $\Omega$ \\
$\mathrm{C}_{2}$ & $1.2377 \times 10^{-8}$ & $\mathrm{~F}$ \\
$\mathrm{R}_{2}$ & 2928 & $\Omega$ \\
\hline
\end{tabular}


Table S3. Values for equivalent circuit elements for n-type PSi sensors in dry conditions and in the presence of various organic solvents.

\begin{tabular}{|c|c|c|c|c|c|}
\hline Sensor & Environment & $\mathbf{R}_{\mathbf{S}} / \mathbf{\Omega}$ & $\mathbf{C} / \mathbf{F}$ & $\mathbf{P}$ & $\mathbf{R}_{1} / \mathbf{\Omega}$ \\
\hline \multirow[t]{16}{*}{ PSi } & Dry & $1 \times 10^{-7}$ & $1.46 \times 10^{-8}$ & 0.8345 & 52182 \\
\hline & Acetone & $1 \times 10^{-7}$ & $5.54 \times 10^{-8}$ & 0.7722 & 32075 \\
\hline & Dry & $1 \times 10^{-7}$ & $1.00 \times 10^{-8}$ & 0.8116 & 61000 \\
\hline & Water & $1 \times 10^{-7}$ & $2.11 \times 10^{-8}$ & 0.7762 & 47000 \\
\hline & Dry & $1 \times 10^{-7}$ & $1.97 \times 10^{-8}$ & 0.8108 & 35722 \\
\hline & Methanol & $1 \times 10^{-7}$ & $2.17 \times 10^{-8}$ & 0.8367 & 18305 \\
\hline & Dry & $1 \times 10^{-7}$ & $6.70 \times 10^{-9}$ & 0.8302 & 25325 \\
\hline & Ethanol & $1 \times 10^{-7}$ & $2.50 \times 10^{-8}$ & 0.8199 & 14502 \\
\hline & Dry & $1 \times 10^{-7}$ & $1.35 \times 10^{-8}$ & 0.8377 & 31401 \\
\hline & Isopropanol & $1 \times 10^{-7}$ & $2.11 \times 10^{-8}$ & 0.8209 & 15215 \\
\hline & Dry & $1 \times 10^{-7}$ & $9.13 \times 10^{-9}$ & 0.8500 & 24680 \\
\hline & Chloroform & $1 \times 10^{-7}$ & $1.49 \times 10^{-8}$ & 0.8215 & 31981 \\
\hline & Dry & $1 \times 10^{-7}$ & $1.35 \times 10^{-8}$ & 0.8397 & 33418 \\
\hline & Toluene & $1 \times 10^{-7}$ & $1.16 \times 10^{-8}$ & 0.8492 & 35473 \\
\hline & Dry & $1 \times 10^{-7}$ & $1.15 \times 10^{-8}$ & 0.8302 & 17554 \\
\hline & Isoprene & $1 \times 10^{-7}$ & $1.83 \times 10^{-8}$ & 0.8043 & 22325 \\
\hline \multirow[t]{6}{*}{$\mathrm{PSi} / \mathrm{Au}_{\mathrm{x}} \mathrm{O}$} & Dry & $1 \times 10^{-7}$ & $1.85 \times 10^{-8}$ & 0.8171 & 54597 \\
\hline & Ethanol & $1 \times 10^{-7}$ & $2.19 \times 10^{-8}$ & 0.8218 & 20857 \\
\hline & Dry & $1 \times 10^{-7}$ & $1.94 \times 10^{-8}$ & 0.8039 & 49888 \\
\hline & Chloroform & $1 \times 10^{-7}$ & $1.97 \times 10^{-8}$ & 0.8038 & 63472 \\
\hline & Dry & $1 \times 10^{-7}$ & $1.94 \times 10^{-8}$ & 0.8039 & 49888 \\
\hline & Toluene & $1 \times 10^{-7}$ & $1.79 \times 10^{-8}$ & 0.8102 & 53328 \\
\hline \multirow[t]{6}{*}{$\mathrm{PSi} / \mathrm{SnO}_{\mathrm{x}}$} & Dry & $1 \times 10^{-7}$ & $5.18 \times 10^{-9}$ & 0.9220 & 75352 \\
\hline & Ethanol & $1 \times 10^{-7}$ & $1.76 \times 10^{-8}$ & 0.8680 & 29157 \\
\hline & Dry & $1 \times 10^{-7}$ & $6.11 \times 10^{-9}$ & 0.8637 & 76477 \\
\hline & Chloroform & $1 \times 10^{-7}$ & $5.29 \times 10^{-9}$ & 0.8525 & 90314 \\
\hline & Dry & $1 \times 10^{-7}$ & $6.66 \times 10^{-9}$ & 0.8610 & 59546 \\
\hline & Toluene & $1 \times 10^{-7}$ & $5.91 \times 10^{-9}$ & 0.8566 & 67844 \\
\hline
\end{tabular}


Table S4. Percentage changes in equivalent circuit elements for p-type PSi sensors upon application of organic solvents.

\begin{tabular}{llllll}
\hline Solvent & $\mathrm{R}_{\mathrm{S}}$ & $\mathrm{C}_{1}$ & $\mathrm{R}_{1}$ & $\mathrm{C}_{2}$ & $\mathrm{R}_{2}$ \\
\hline Acetone & $0 \%$ & $111 \%$ & $-34 \%$ & $120 \%$ & $42 \%$ \\
Water & $0 \%$ & $3 \%$ & $-14 \%$ & $14 \%$ & $-18 \%$ \\
Methanol & $0 \%$ & $33 \%$ & $4 \%$ & $536 \%$ & $-65 \%$ \\
Ethanol & $0 \%$ & $60 \%$ & $-37 \%$ & $125 \%$ & $-59 \%$ \\
Isopropanol & $0 \%$ & $28 \%$ & $-25 \%$ & $143 \%$ & $-51 \%$ \\
Chloroform & $0 \%$ & $-1 \%$ & $18 \%$ & $11 \%$ & $26 \%$ \\
Toluene & $-1 \%$ & $1 \%$ & $3 \%$ & $8 \%$ & $3 \%$ \\
Isoprene & $0 \%$ & $-15 \%$ & $19 \%$ & $-9 \%$ & $83 \%$ \\
\hline
\end{tabular}
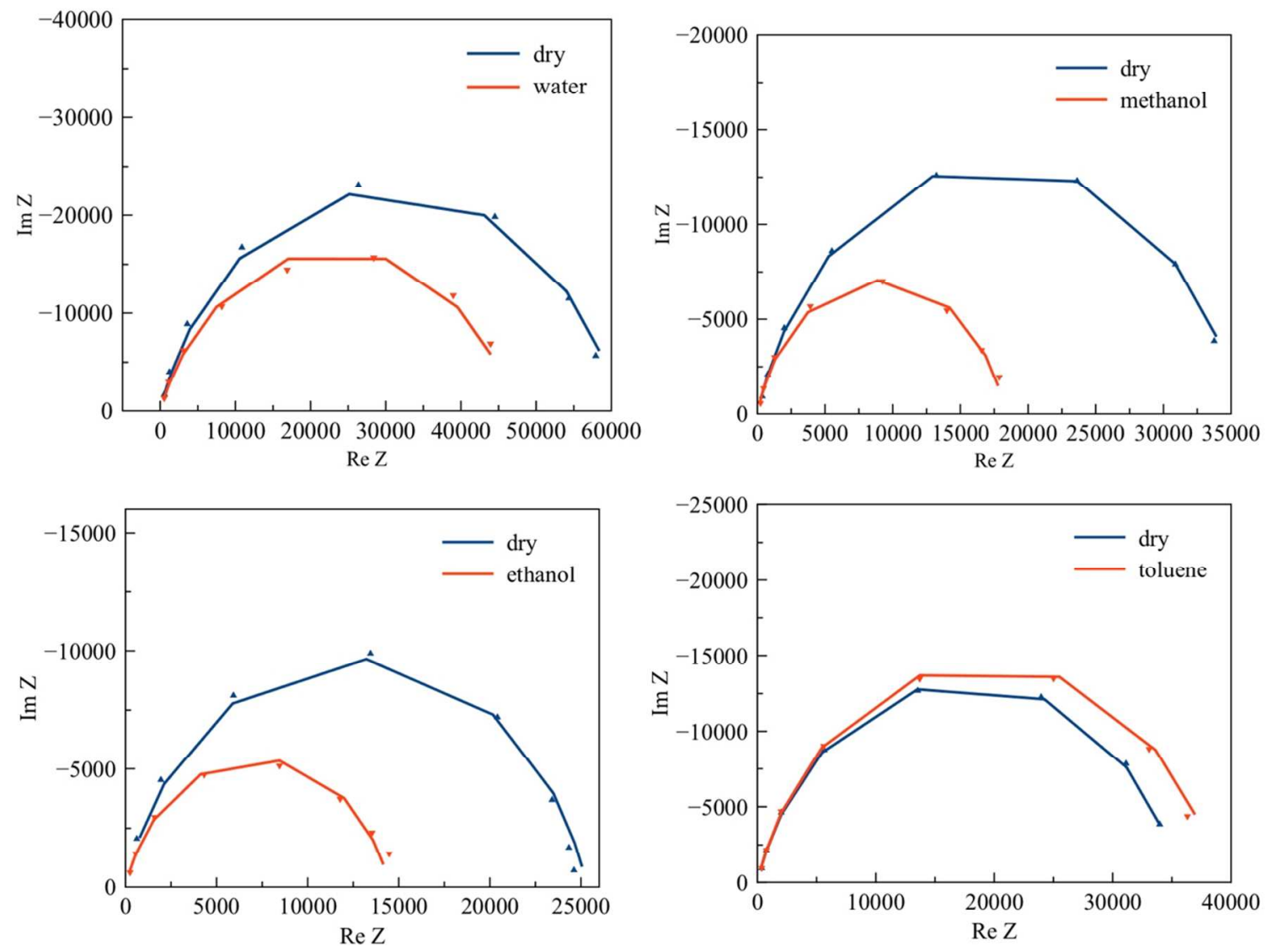

Figure S2. Complex impedance plots (Nyquist plots) of n-type PSi sensors comparing dry conditions (blue) and upon exposure to various polar and non-polar organic solvents (orange). The experimental data is shown as triangle markers and the fitted equivalent circuit simulation is shown as a solid line. 

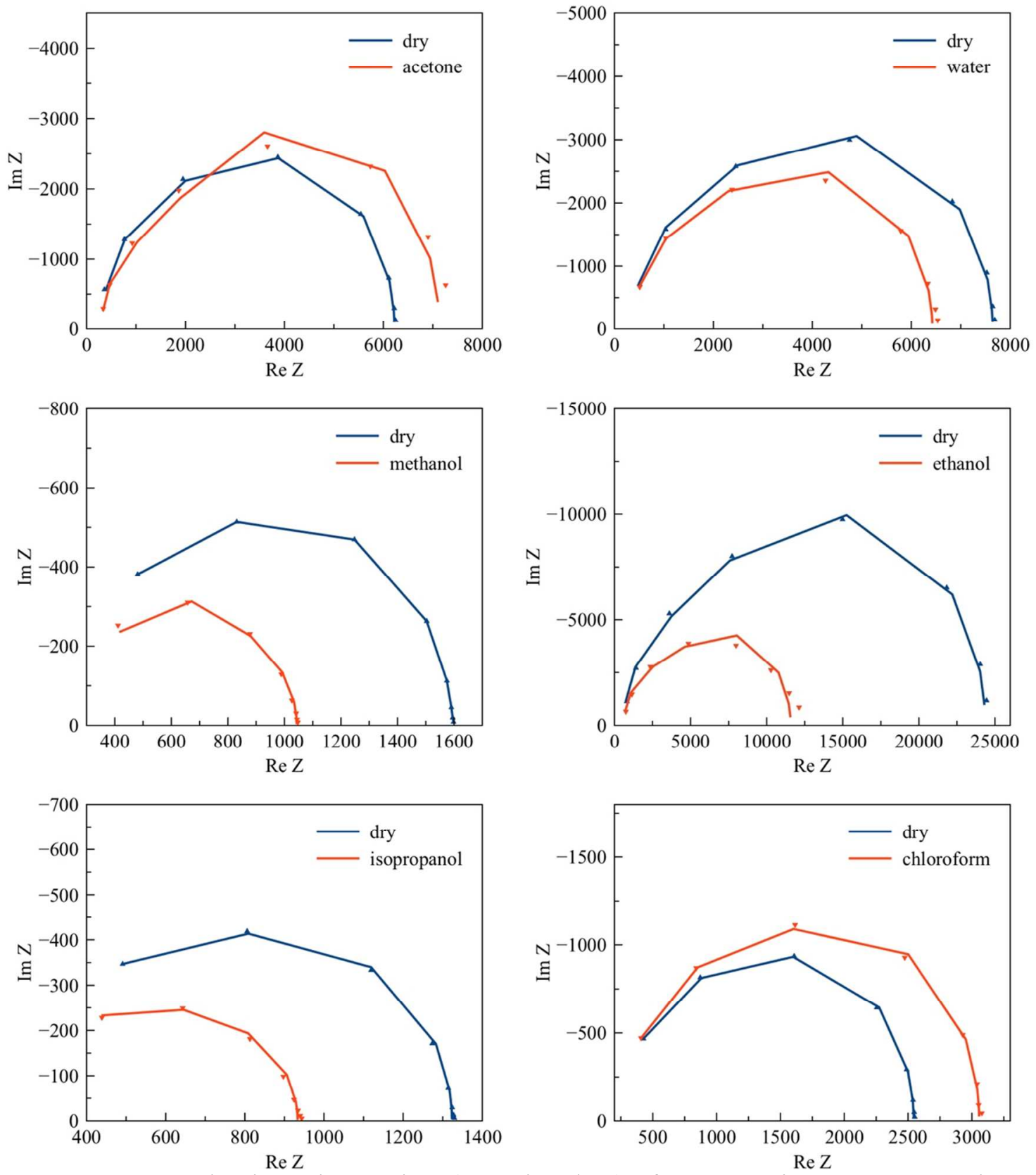

Figure S3. Complex impedance plots (Nyquist plots) of p-type PSi sensors comparing dry conditions (blue) and upon exposure to various polar organic solvents (orange). The experimental data is shown as triangle markers and the fitted equivalent circuit simulation is shown as a solid line. 

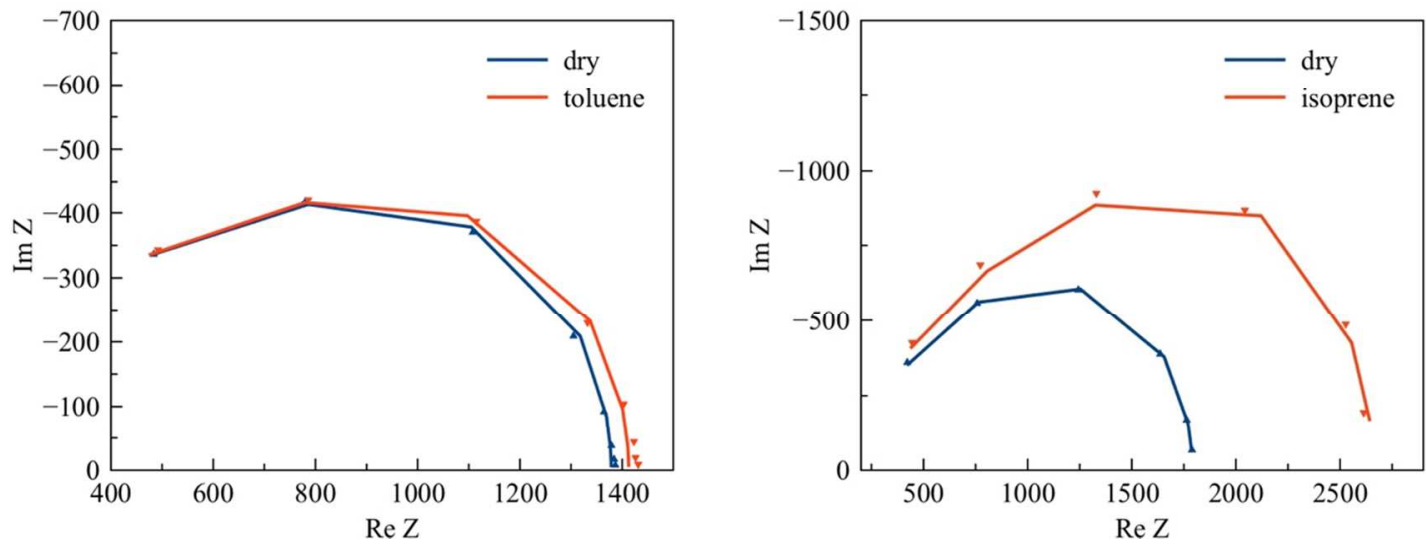

Figure S4. Complex impedance plots (Nyquist plots) of p-type PSi sensors comparing dry conditions (blue) and upon exposure to various non-polar organic solvents (orange). The experimental data is shown as triangle markers and the fitted equivalent circuit simulation is shown as a solid line.

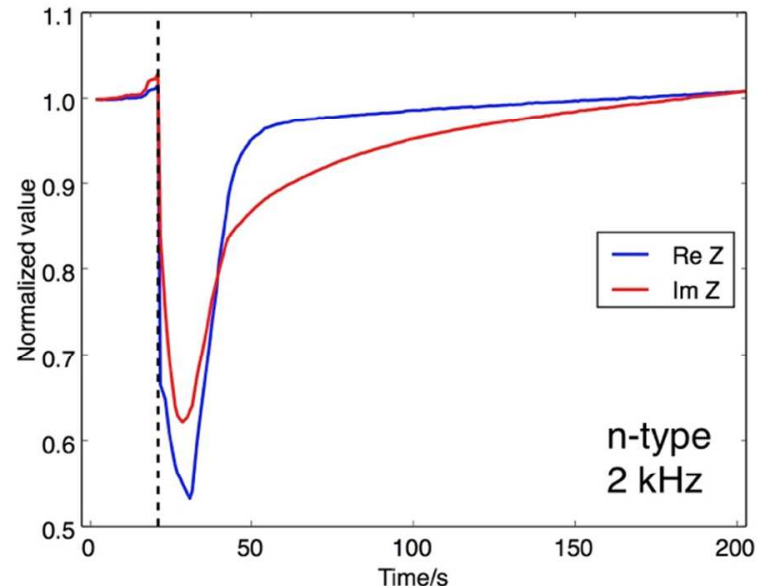

(a)

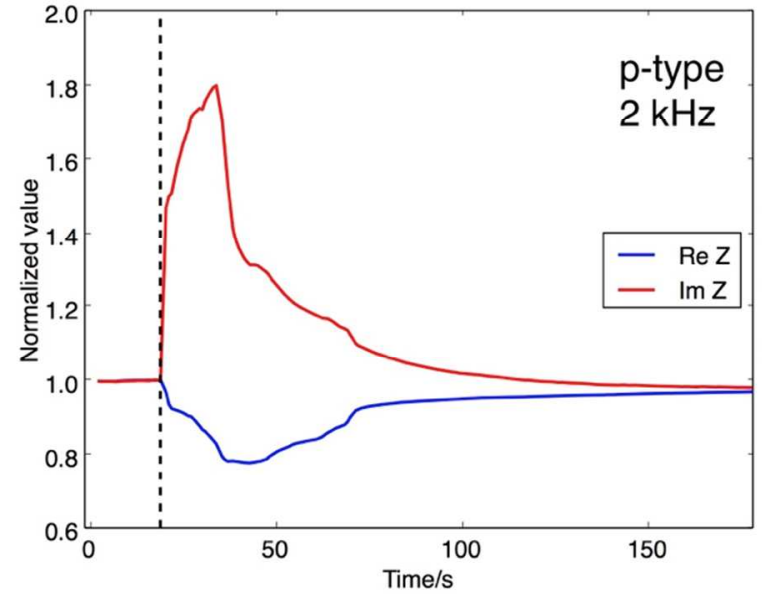

(c)

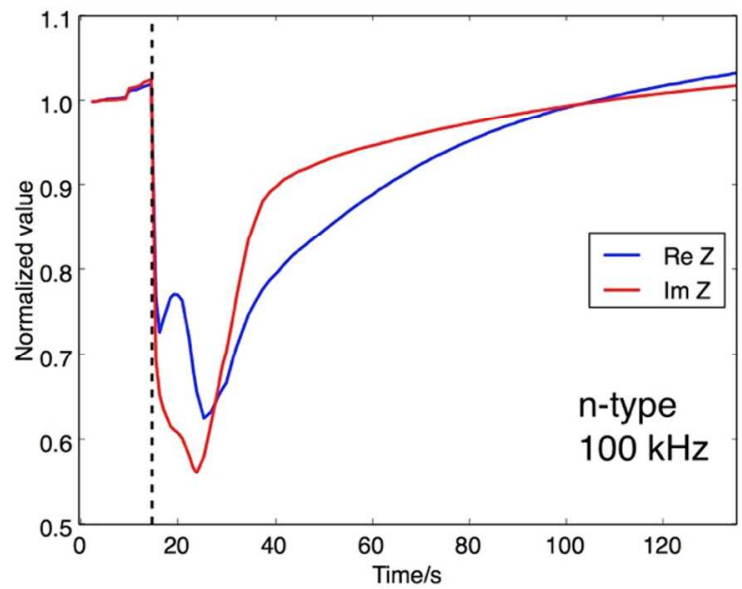

(b)

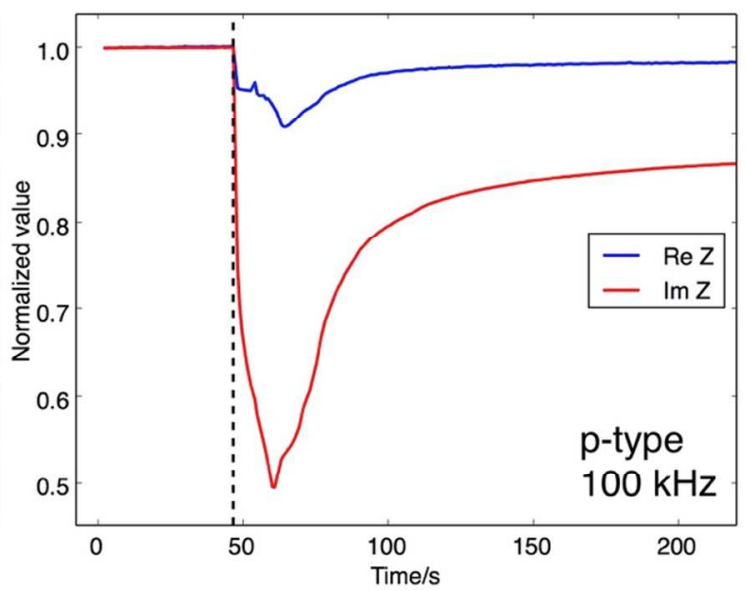

(d)

Figure S5. The real (blue) and imaginary (red) part of impedance of (a,b) n-type and (c,d) p-type PSi sensors upon exposure to acetone at (a,c) $2 \mathrm{kHz}$ and (b,d) $100 \mathrm{kHz}$. The vertical dashed line indicated the time at which the solvent was placed onto the PSi sensor. 

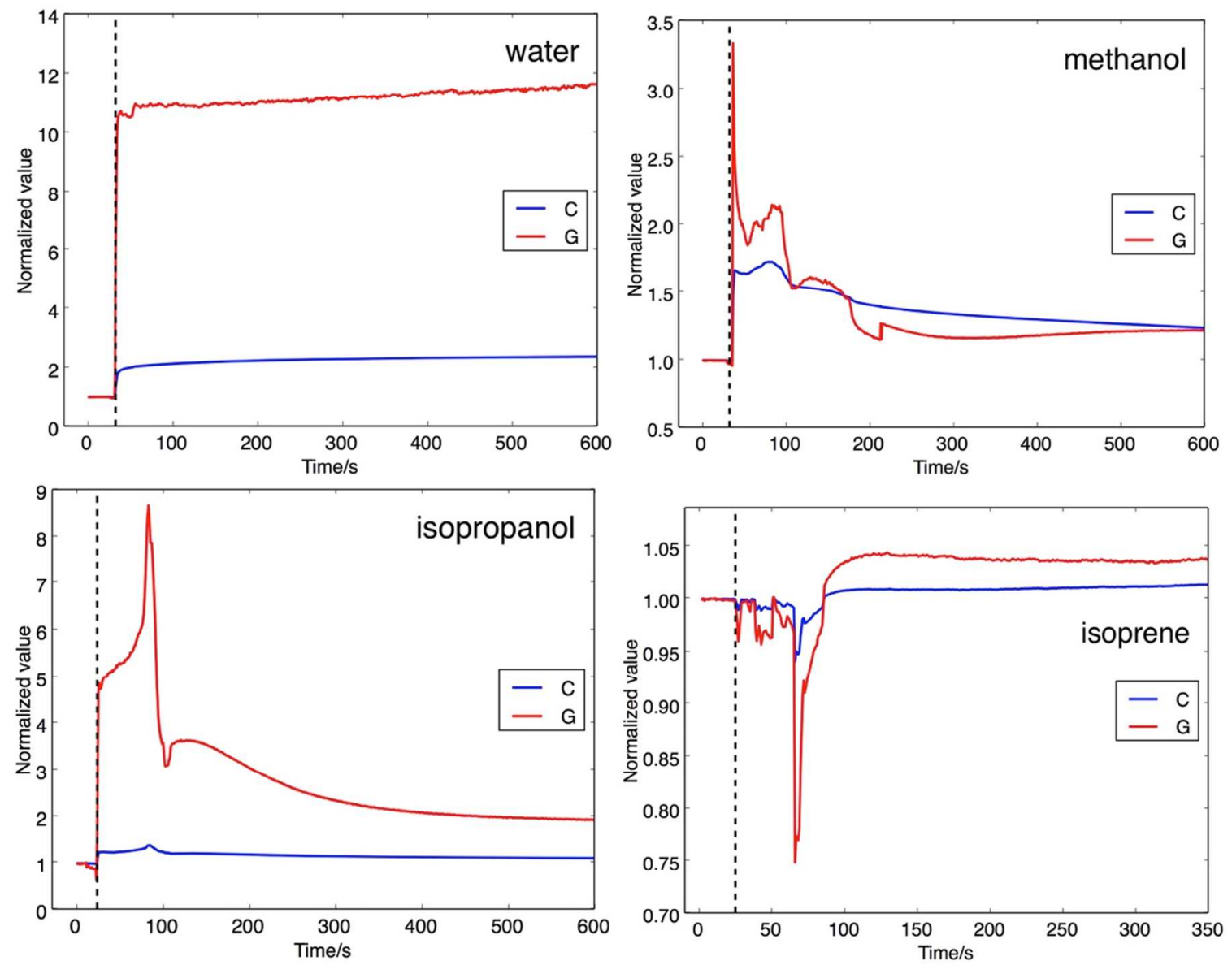

Figure S6. Conductance (red) and capacitance (blue) of n-type PSi sensors upon exposure to various polar and non-polar organic solvents. The vertical dashed line indicated the time at which the solvent was placed onto the PSi sensor. 

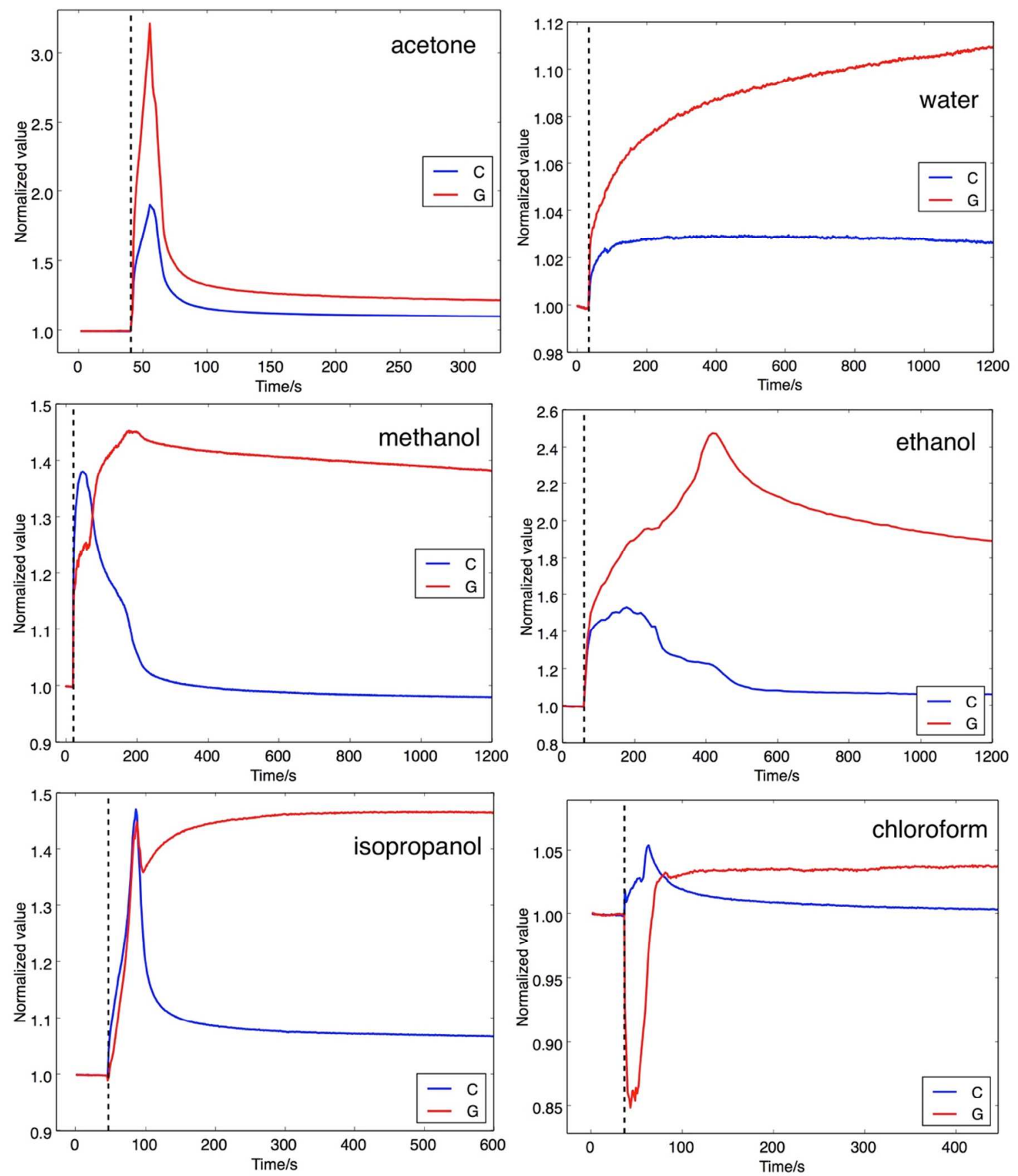

Figure S7. Conductance (red) and capacitance (blue) of p-type PSi sensors upon exposure to various polar organic solvents. The vertical dashed line indicated the time at which the solvent was placed onto the PSi sensor. 

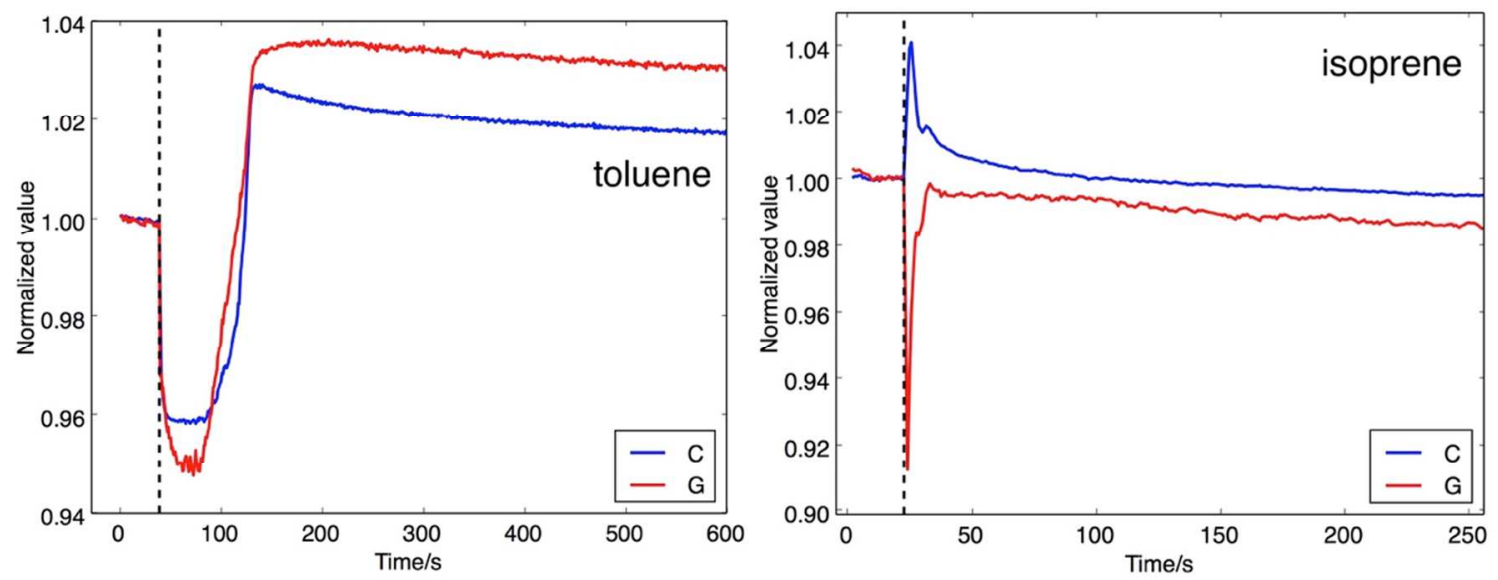

Figure S8. Conductance (red) and capacitance (blue) of p-type PSi sensors upon exposure to isoprene. The vertical dashed line indicated the time at which the solvent was placed onto the PSi sensor.

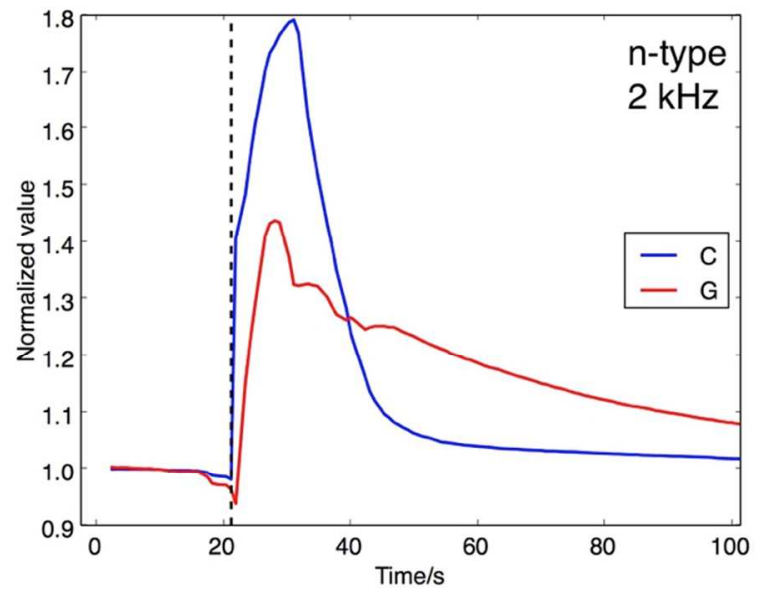

(a)

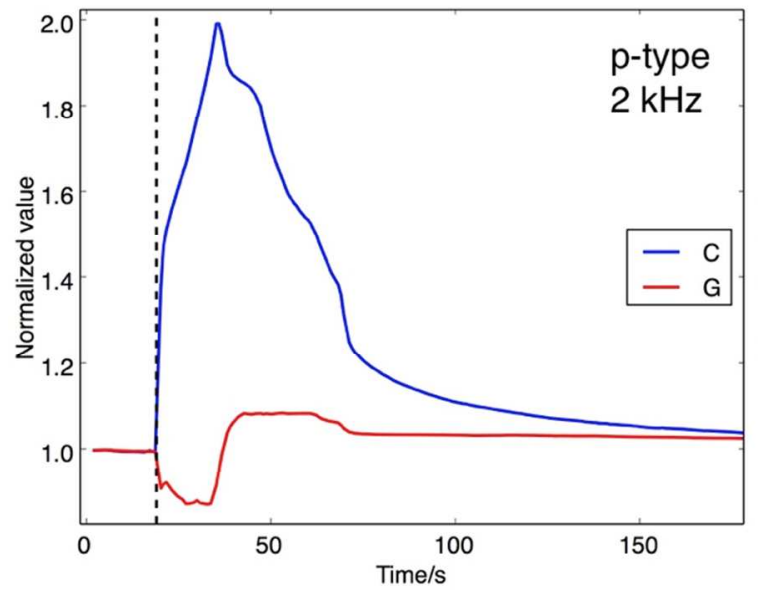

(c)

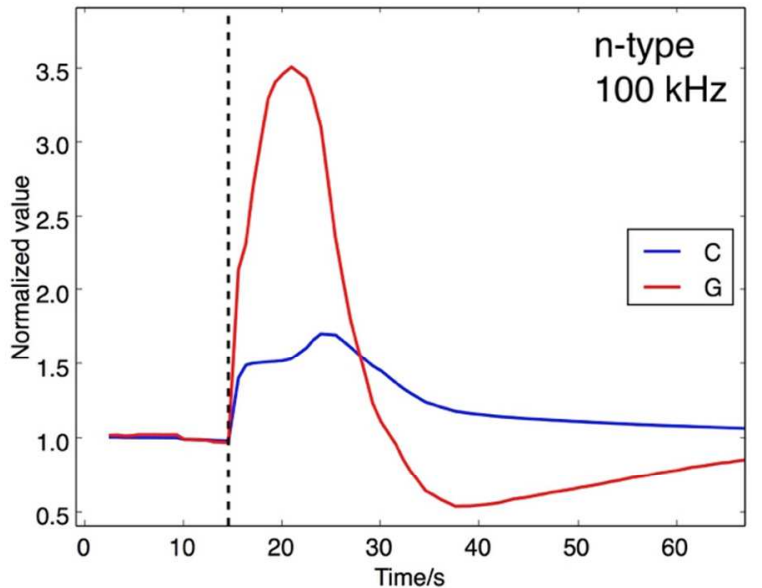

(b)

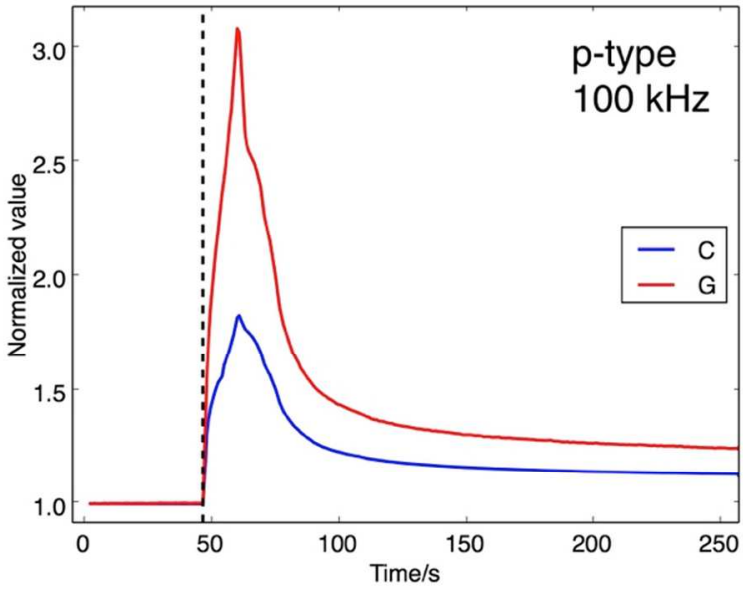

(d)

Figure S9. The capacitance (blue) and conductance (red) of (a,b) n-type and (c,d) p-type PSi sensor upon exposure to acetone at $(\mathrm{a}, \mathrm{c}) 2 \mathrm{kHz}$ and $(\mathrm{b}, \mathrm{d}) 100 \mathrm{kHz}$. The vertical dashed line indicated the time at which the solvent was placed onto the PSi sensor. 

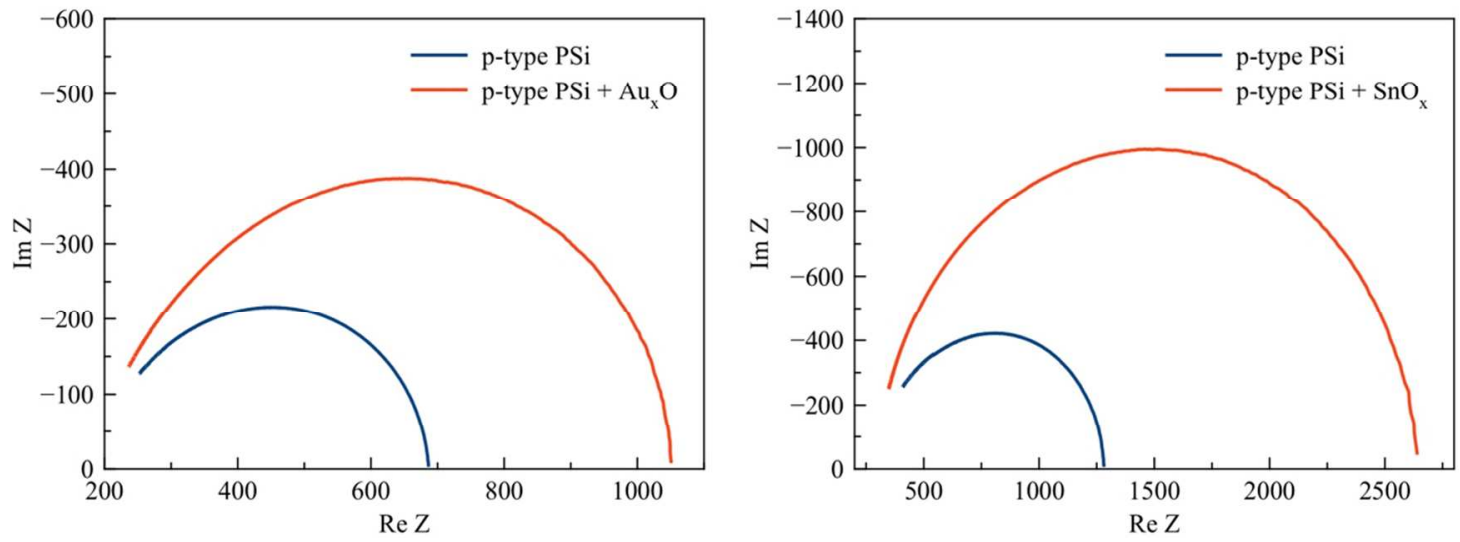

Figure S10. Complex impedance plots (Nyquist plots) of p-type PSi sensors in dry conditions comparing before and after decoration with $\mathrm{Au}_{\mathrm{x}} \mathrm{O}$ nanostructures and $\mathrm{SnO}_{\mathrm{x}}$ nanostructures.

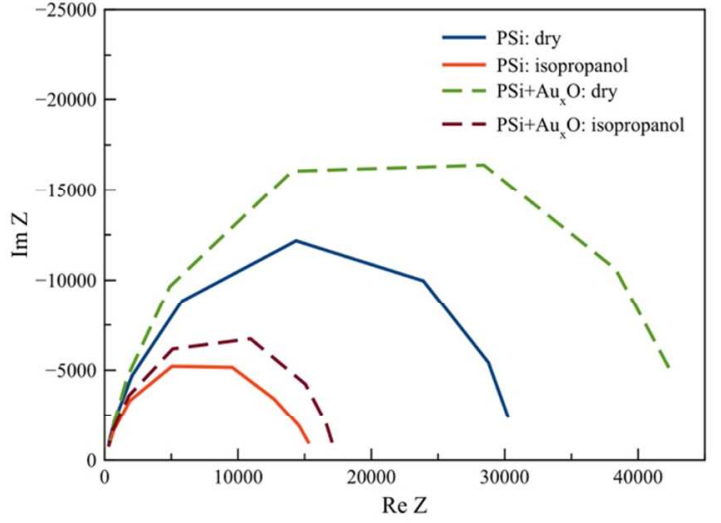

(a)

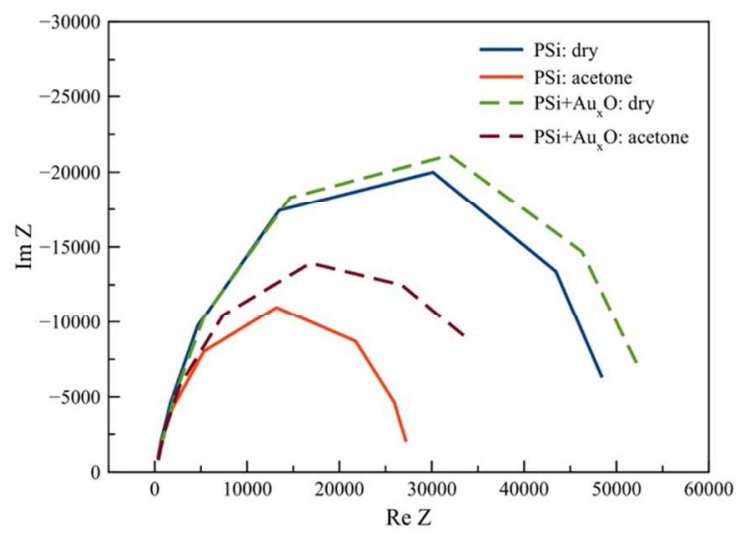

(c)

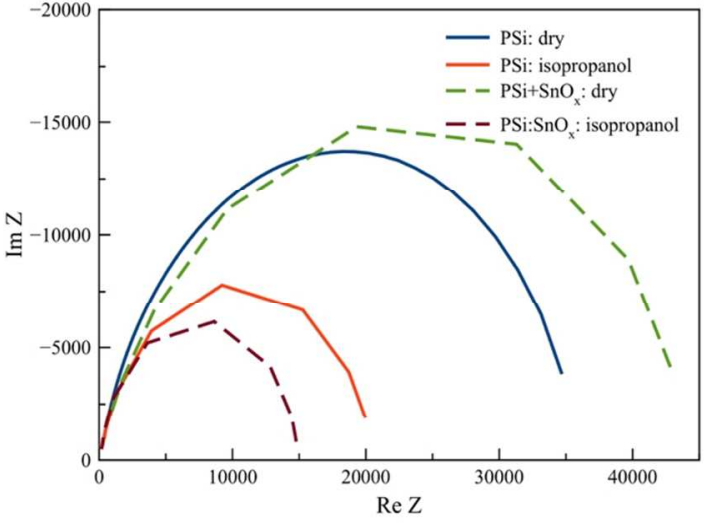

(b)

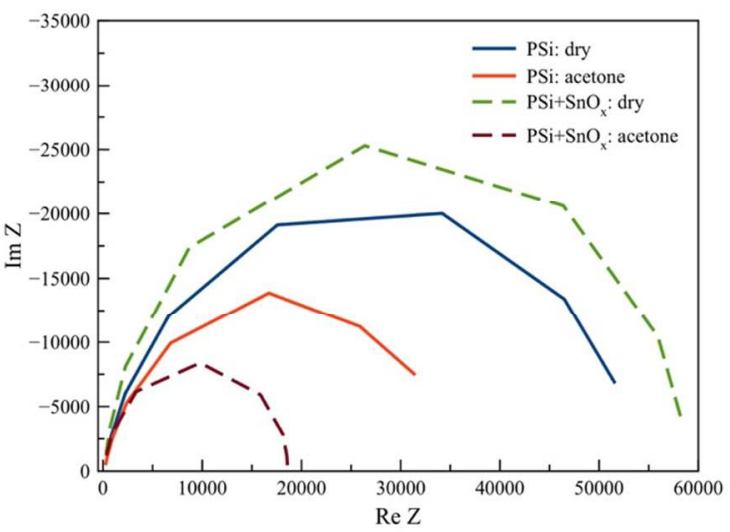

(d)

Figure S11. Complex impedance plots (Nyquist plots) of n-type PSi sensors in dry conditions and in the presence of $(a, b)$ isopropanol and $(c, d)$ acetone, comparing before and after decoration with $(\mathrm{a}, \mathrm{c}) \mathrm{Au}_{\mathrm{x}} \mathrm{O}$ nanostructures and $(\mathrm{b}, \mathrm{d}) \mathrm{SnO}_{\mathrm{x}}$ nanostructures. 


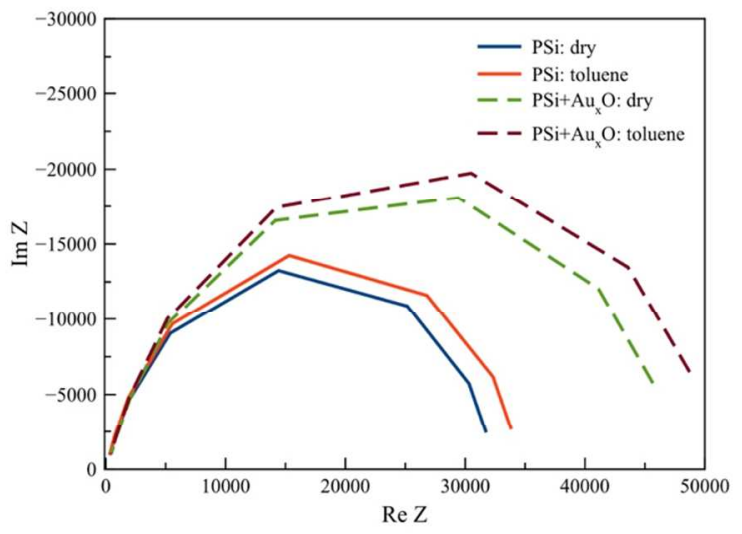

(a)

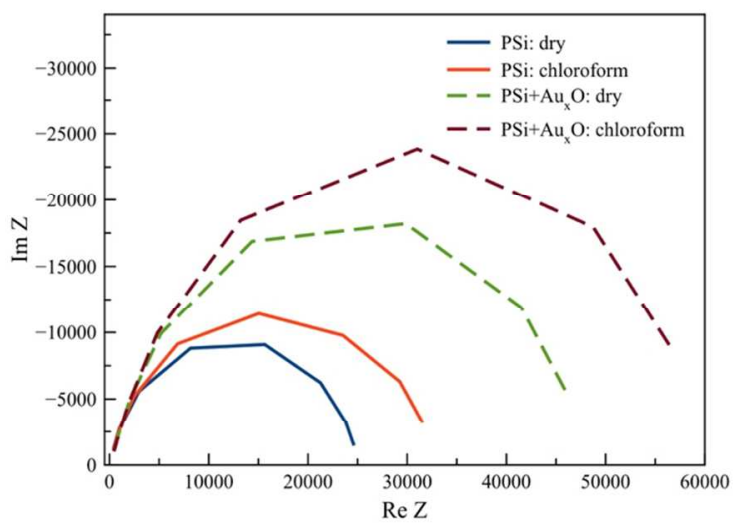

(c)

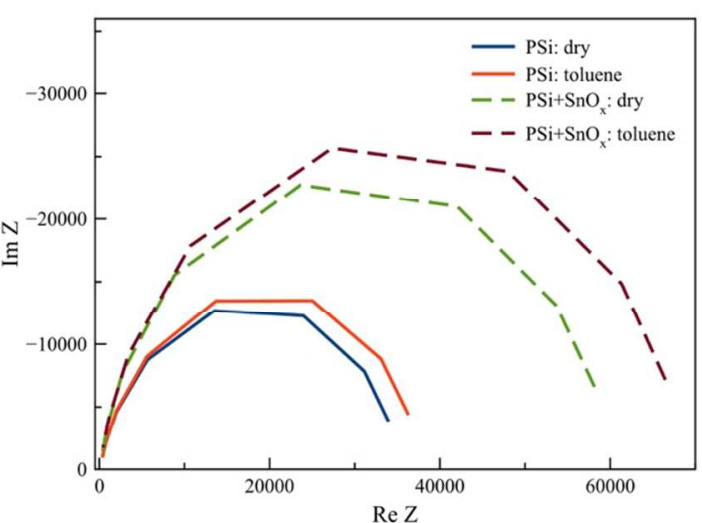

(b)

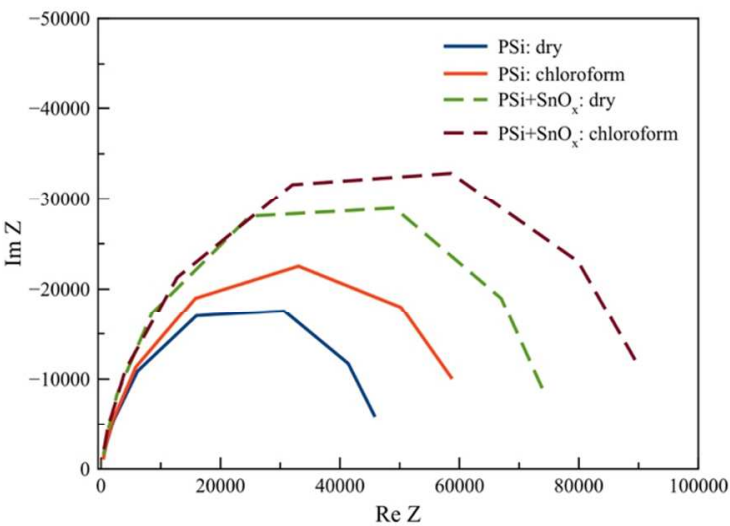

(d)

Figure S12. Complex impedance plots (Nyquist plots) of n-type PSi sensors in dry conditions and in the presence of $(a, b)$ toluene and $(c, d)$ chloroform, comparing before and after decoration with $(\mathrm{a}, \mathrm{c}) \mathrm{Au}_{\mathrm{x}} \mathrm{O}$ nanostructures and $(\mathrm{b}, \mathrm{d}) \mathrm{SnO}_{\mathrm{x}}$ nanostructures. 